\title{
Emerging literacy from kindergarten to second grade: Evidence from the Munich Longitudinal Study on the Genesis of Individual Competencies
}

\author{
Jan Carol Näslund \\ Wolfgang Schneider
}

The opportunity to closely study children's cognitive and affective development longitudinally for five years rarely presents itself. When this opportunity does arise, careful planning for exact methods and content of data collection weighs heavily on researchers' minds. However, at the same time, such an undertaking necessarily requires the flexibility to alter, and sometimes change direction in order to keep up-to-date with new findings found in the literature and (most often) as a result of personal insights and innovations. The Munich Longitudinal Study for the Genesis of Individual Competencies (Weinert/Schneider 1987, 1991, 1992) provided the team of researchers at the Max Planck Institute for Psychological Research in Munich such an opportunity.

The collection of data in the area of cognitive development for this project provided the foundation on which the study of later emergent literacy was based. This paper will focus only on a subset of cognitive factors which affect reading acquisition. These cognitive areas are: 1) memory development, 2) general and verbal intelligence, and 3) metalinguistic competencies. Memory and intelligence were first assessed at about age four (at the beginning of kindergarten), and again with metalinguistic competencies, and early letter knowledge at age six (in the last year of kindergarten). After children entered first grade, and began to learn to read formally, memory, intelligence, and metalinguistic skills were assessed again in addition to reading performance.

Other longitudinal studies assessing the influence of preschool cognitive factors on later reading performance have been completed recently (Juel 1988; Lundberg/Frost/Peterson 1988; Maclean/Bryant/Bradley 1987). These studies indicate preschool metalinguistic awareness to be a major factor in emerging literacy and later reading performance in school. However, there is some indication that metalinguistic awareness at the level of phonological 
segmentation covaries with children's learning the alphabetic principle (Foorman/Francis/Novy/Liberman 1991; Perfetti/Beck/Bell/Hughes 1987). Ehri (1989), Morais/Cary/Alegria/Bertelson (1979), and Read/Zhang/Nie/ Ding (1986) provide evidence that phonological segmentation skills do not arise in the absence of some formal instruction in the alphabetical principle. However, Lundberg et al.'s (1988) longitudinal training study of Scandinavian children demonstrates that phonological segmentation skills can develop independently of specific literacy instruction. Some forms of metalinguistic awareness may actually be necessary to learn the alphabetic principle (an hypothesis supported by Tunmer/Rohl 1991).

German and Scandinavian school children similarly begin formal training in reading at later ages than in other industrialized countries. Whereas children in the British system begin reading instruction at about age four, the age for Scandinavian and German children is about age six and a half or seven. This difference may be responsible for some of the recent inconsistent findings pertaining to possible causal influences of phonological segmentation and alphabetic knowledge. Results of the study reported here with German children adds to the evidence in favor of preliterate phonological awareness development, and differentiates phonological awareness tasks as to their relative dependency on alphabetic knowledge.

Pioneering research beginning about fifteen years ago and conducted at the Haskin Laboratories under the direction of Isabelle Liberman has led to breakthroughs in discovering cognitive factors which specifically affect reading development (Brady/Shankweiler/Mann 1983; Liberman/Shankweiler/Liberman et al. 1977; Mann/Liberman/Shankweiler 1980; Mark/ Shankweiler/Liberman/Fowler 1977). These researchers provide convincing evidence that reading performance is related to working memory via phonological recoding of text. Memory span alone does not explain differences in performance among poor and better readers. Better readers appear to phonologically recode verbal information, increasing the efficiency of their working memory. Poorer readers phonologically recoded verbal information to a lesser extent than better readers, and this is believed to explain in part their less efficient working memory while reading. The evidence for this phonological recoding effect came from findings that better readers were adversely affected in their recall of verbal information if this information contained phonologically similar items (letters, words, sentences) in comparison to recall for phonologically dissimilar items. Poorer readers were less adversely affected in recall by phonologically similar lists of information in comparison with phonologically dissimilar lists of infor- 
mation. The observed phonological interference effect for better readers was the basis for proposing that phonological recoding in working memory was likely a significant cognitive component in reading. Better readers appeared to spontaneously and automatically phonologically recode information, whereas poorer readers did this less so. The developmental relationship between memory and phonological awareness is also a focus of this paper. If phonological awareness arises independently of alphabetic knowledge, then one would expect that the relationship between phonological awareness and memory would also arise independently of alphabetic knowledge.

Stanovich/Cunningham/Feeman (1984) have shown that phonological awareness influences reading comprehension indirectly through its direct effect on text decoding. The finding that both pseudoword and word reading predicted reading comprehension suggested that a child's facility with phonological recoding of text was in large part responsible for their reading performance. This result, in addition to those found by Isabelle Liberman and colleagues suggests that better readers cognitively process phonological components of text as they read, whereas poorer readers process phonological components less so.

In a review and critique of whole-language and code-oriented approaches to reading instruction, Vellutino (1991) has argued that good readers use phonological recoding more than poorer readers, and that poorer readers tend more than good readers to use less efficient context strategies. Wholelanguage refers to an instructional approach with the major premise being that reading is a "psychological guessing game" (Goodman 1967). Teachers are discouraged from teaching phonetics of any kind. (Phonetics refers to any teaching of phonemic properties of letters and letter clusters, such as syllabic or onset/rime units. Traditional phonics refers to teaching that each letter corresponds to one, or sometimes two - in the case of some languages - individual sounds.) Children are encouraged to use contextual cues in "guessing" the meaning of text. The major goal is to teach reading without disturbing the "whole-ness" of language. Contemporary code-oriented approaches make use of more phonetic approaches in teaching decoding of text. In the more accepted phonetic techniques, perceptual phonological units are preserved. For example, $/ b /$ is only an abstract phoneme, given that it can only be detected in combination with a vowel, such as when comparing the difference heard in $/ \mathrm{bi} /$ and $/ \mathrm{i} /$. Recent attempts to advocate a mixture of whole-language and code-oriented teaching ignores the basic tenet of whole-language. As soon as any decoding is taught, the approach ceases to be whole-language. Findings from longitudinal studies of reading acquisition 
are pertinent to the conflict surrounding whole-language and code-oriented approaches. Such studies can help reveal the cognitive development of children as they enter into reading instruction, especially if the early stages of the study take place before most children are taught the alphabet. Vellutino's (1991) argument concerning the importance of code-based instruction would be supported by longitudinal findings showing that preliterate children's level of phonological awareness, independent of alphabetic knowledge and verbal aptitude, explained a significant proportion of their later reading performance. If better readers spontaneously develop phonological awareness, and use this to become proficient readers, this would suggest that reading instruction encouraging attention to phonological properties of language should be encouraged.

In summary, this paper focuses on several specific concerns in emerging literacy. First, we compare the predictive relationship of preschool verbal and general intelligence, verbal memory, metalinguistic skills, and decoding on reading comprehension in the early grades. Second, the relationship between memory and phonological awareness is assessed developmentally. Third, the relative independence of metalinguistic awareness and alphabetic knowledge is assessed.

\section{Method}

The original sample included 220 children from Munich and surrounding suburbs. Beginning at about age four, children visited one of two test sites two or three times during the school year (one in Munich and one in a nearby suburb). The major goal of the LOGIC project was to assess intraindividual changes in a variety of cognitive and social skills, and to explore the pattern of change in these interrelationships over time (cf. Weinert/ Schneider 1987). One of the subgoals of the study concerned the prediction of reading acquisition, which is the topic of the present paper. The analyses reported below include the first five years of the study, ending when most children were in the second grade. Not all 220 children are included in the analyses presented here. Due to organizational problems, a subgroup of children were not tested on the word and nonword decoding speed tests and the reading comprehension tests to be described below. For various reasons, 21 subjects were not promoted to first grade at the time most other children were, and were omitted from analyses concerning school-related tasks. There were absentees on some of the testing days, and some children chose to dis- 
continue their participation in the study. As a consequence, the following analyses are based on those 133 subjects with complete data sets.

\section{Description of assessments}

As noted above, several cognitive measures of the LOGIC study that were assessed at different points in time seemed suitable as predictors of reading acquisition. These measures are summarized below.

\section{Age four:}

Columbia Mental Maturity Scale (CMMS). The American version of the CMMS (Burgemeister/Blum/Lorge 1972) was adopted for the LOGIC study because the German version of the test cannot be used with kindergarten children. Children were presented with pictorial and figural classification items. Each item consisted of three to five drawings. The children's task was to look at all the pictures on the card, select the one that was different from or unrelated to the others, and to indicate their choice by pointing to it. The number of correct choices was taken as a measure of children's nonverbal intellectual ability.

Word Span. An German adaptation of the word span task given by Case/ Kurland/Goldberg (1982) was administered to assess children's memory capacity. The items to be recalled in the word lists were all concrete nouns. The lists to be recalled ranges in length from three to seven words. Children were first given a list of three words to recall. If children recalled two sets of three words each correctly, two lists of four words each were presented. Children were given successively more words to recall only if they recalled at least one set at the previous level.

A second word span was also devised. The lists were so constructed that words in each list would sound similar, either by rhyming, or by having the same first sound.

Assessments at age five:

Hannover-Wechsler Intelligence Scale for Kindergarten Children (HAWIVA, Eggert 1978). This test represents the German adaptation of the Wechsler Intelligence Test for Children (WISC) for four- to six-year-old children. The verbal section (verbal comprehension, word usage and vocabulary, and general knowledge) of this inventory was used in these analyses, yielding a sum score that represented children's verbal intelligence. 
Assessments at age six:

Battery of metalinguistic tasks. A battery of meta-linguistic tasks for preschool children devised by Jansen/Knorn/Mannhaupt et al. (1986; see also Skowronek/Marx 1989) and Brügelmann (1986) was adopted for the LOGIC study. In addition to these, a German version of Bradley/Bryant's (1985) phonological oddity (rhyming) task was also administered in the last kindergarten year. In the second grade, children received a phonological awareness and segmentation inventory devised by the first author. Tasks taken from the Jansen et al. (1986) battery were: repetition of nonsense words, detecting word pairs that rhyme, syllable counting, blending two syllables to make a word, and detecting particular sounds within words. The tasks used from Brügelmann's (1986) inventory were syllable segmenting of words and syllable synthesizing (identifying words which were pronounced with elongated vowels). The Bradley/Bryant (1985) tasks consisted of identifying which word of four either differed in initial consonant, or in the middle vowel, or did not rhyme with the other three.

Word span. The word span test developed by Case et al. (1982) and described above was administered again. The second memory span test was also repeated at this measurement point.

Sentence span. A German version of the listening span test developed by Daneman/Blennerhassett (1984) was additionally used to assess children's memory capacity. Groups of sentences (ranging from one to seven sentences) were presented to children. The total number of sentences correctly recalled was used for children's score on this measure.

Columbia Mental Maturity Scale (CMMS, Burgemeister/Blum/Large 1972). This test was identical to the one presented at age four and was given as a non-verbal intelligence measure.

Alphabetic knowledge. This was an assessment also taken from the Jansen et al. (1986) inventory of preschool predictors of reading performance. Children were shown letters in a fixed random order and asked if they recognized any of them, and if so, to name them. For purposes of this paper, answers were considered correct if either the letter name or sound were correctly identified.

\section{Assessments at age seven:}

Hamburg Wechsler-Intelligence Scale for School Children (HAWIK, Tewes 1985). This is the age-corrected form of the HAWIVA described above. Again, the verbal part was used for purposes of this study and taken as an indicator of verbal intelligence.

The Sentence span given at age five was repeated at age seven.

Word Discrimination. Whereas the previous measures were used as predic- 
tors of reading skills, the word discrimination test given at the end of the first year in elementary school was chosen to assess children's early reading skills. Children were presented with four sets of pictures of familiar objects (i.e., an eye, house, cow, etc.). After correctly identifying the pictures, children were then asked to watch the screen of a table-top slide projector very carefully. The pictures remained in front of the child during each set of trials. They were to read the word flashed on the screen (shown for $1 \mathrm{sec}-$ ond) and indicate if the word corresponded to one of the pictures that was in front of them, and if so, to point to the picture. Distractor words were phonologically and visually similar to the target words (i.e., for the target "Apfel", "Ampel" was one of the distractor words).

Assessments at age eight:

The CMMS, Word span, and Sentence span tasks described previously were repeated at age eight.

Phonological awareness and segmentation. An inventory of phonological awareness and segmentation tasks was devised by the first author. These tasks were more difficult than those administered in the preschool metalinguistic awareness inventory. The first task required identifying altered phonemes between sets of pseudowords. The second task required replacing phonemes in pseudowords, and third task required switching phonemes within pseudowords. The scores of all of these tasks are combined for the second grade phonological awareness variable.

Word and non-word decoding speed. This task was administered at the beginning and end of second grade. Children were presented with onesyllable real words and pseudowords on a computer screen. Letters were about four inches high. A computer timer was activated as soon as each word or pseudoword appeared on the screen. Speed of decoding was recorded when the research assistant pressed the space bar as the child was pronouncing the last sound in each target. Onset speed was not used in this case given that pilot work indicated that many children pronounced the first sound of the words presented whether or not they recognized the word. Serial pronunciation of letters is possible in German, and therefore onset time does not necessarily indicate word recognition or decoding.

Reading comprehension. The reading comprehension test devised by the first author was administered at the beginning and end of second grade. 18 items were intended to measure word identification within the context of a sentence. Close-type multiple choice format was used. The second part of the test consisted of reading five short stories and responding to a total of 12 multiple choice comprehension items, intended to require inferences based on the text. 


\section{Predicting later reading performance}

\section{Kindergarten and second grade predictors}

A first aim of this study was to estimate and test a structural (causal) model describing and explaining individual differences in reading acquisition. In order to increase the reliability of findings, a latent variable structural equation model using multiple indicators of particular factors was specified. In the case of predicting reading comprehension, the four proposed predictive factors are verbal ability, memory capacity, phonological awareness, and decoding speed. Decoding speed is also believed to be predicted by phonological awareness. In addition, both decoding speed and phonological awareness are themselves proposed as being predicted by memory capacity and verbal ability.

At least two separate measures were administered for each of the factors proposed to influence reading performance. The same predictive factors (memory capacity, phonological awareness, and verbal ability) were measured by several tasks each in kindergarten and in early elementary school (see Näslund/Schneider 1991). The latent memory capacity factor comprised the word span tasks (phonologically similar and dissimilar word lists). The latent phonological awareness variable consisted of the first and last sound oddity tasks, and the syllable blending task. The verbal ability factor consisted of the vocabulary and verbal comprehension subtests of the HAWIVA and HAWIK inventories. The purpose of two measurement points, one before and one after the start of formal reading instruction, was to assess the viability of the proposed structural model and the persistence of influence of the predictive factors before and after the start of formal reading instruction.

Linear Structural Relationships modelling (LISREL VI, Jöreskog/Sörbom 1984) was used to test these and some alternate hypotheses about the likely causal relationships among these factors and reading comprehension. LISREL analyses are specifically designed to directly test hypotheses (for details see Näslund/Schneider 1991; Schneider/Näslund 1992). The proposed structural model for each time period is found in Figure 1.

Models tested. Verbal ability and memory capacity were conceived of as primary sources of influence on the rest of the latent predictive and criterion variables. Preliminary analyses revealed that phonological awareness was 


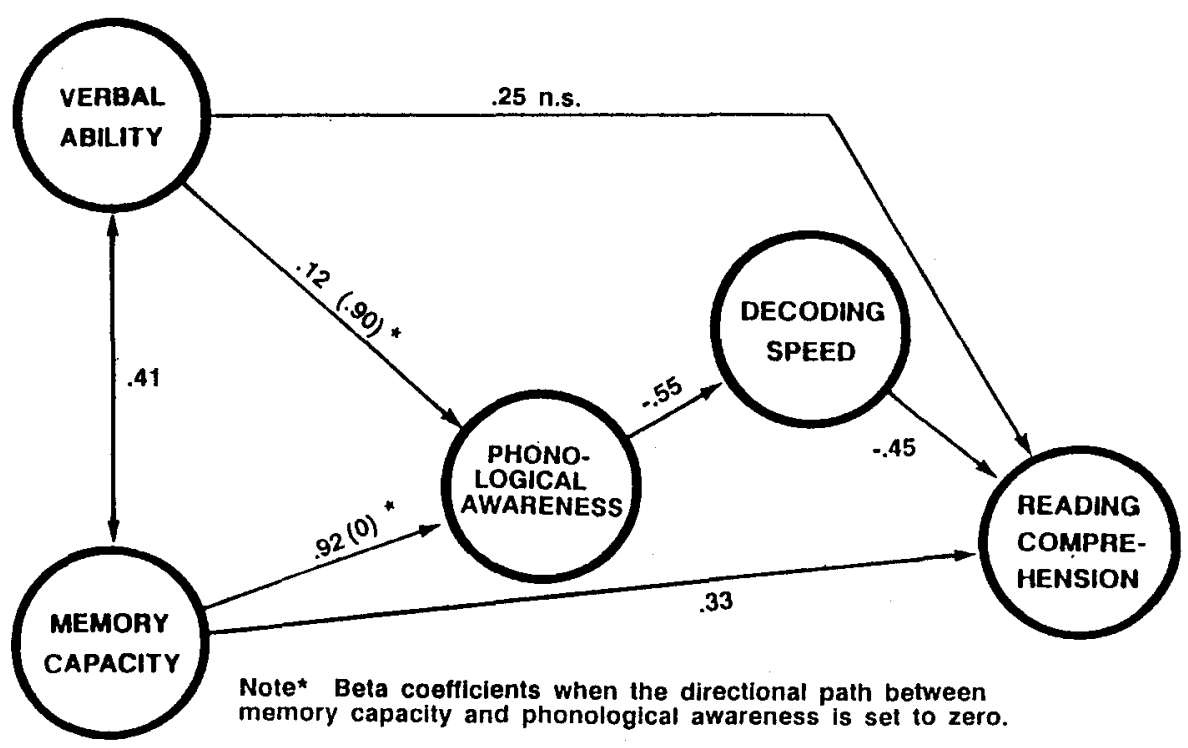

Fig. 1: LISREL model for preschool predictors of second grade decoding speed and reading comprehension

likely to be significantly influenced by memory capacity, and possibly verbal ability. Although memory capacity was strongly correlated to all other factors in the model, the direct connections between memory capacity and decoding speed were not significant in this particular model. The directionality between memory capacity and phonological awareness developed into an issue in this study, and will be addressed more directly in the next section of this paper. Decoding speed, as demonstrated in the literature, was proposed to be directly influenced by phonological awareness, and in turn decoding speed was proposed to have a direct influence on reading comprehension. Verbal memory capacity has repeatedly been shown to have a strong relationship with reading comprehension. Therefore, this direct influence is also tested in the model, and compared with the direct effects of verbal ability on reading comprehension.

This particular model fitted the observed measured variables acceptably when it included the kindergarten factors $\left(\chi^{2}=37.86, p=.15\right)$. However, the influence of verbal ability on both phonological awareness and reading comprehension were not strong enough to be significant (see Figure 1). The 
rest of the proposed relationships were significant. In order to test the strength of memory as an influence on phonological awareness and reading, the proposed relationship between memory capacity and phonological awareness was set to be zero. This one change caused the model to have unacceptable fit $\left(\chi^{2}=49.51, p<.05\right)$. This result attests to the importance of memory as a preschool factor in development of skills related to success in reading.

The same procedure was applied to the model containing the elementary school predictive factors (see Figure 2). This analysis included reading comprehension and decoding measures administered at the end of second grade. The same results emerged, except that there was no significant direct effect of memory capacity on reading comprehension as found for preschool memory capacity $\left(\chi^{2}=29.60, p=.13\right)$. Deleting the proposed connection between memory capacity and phonological awareness also had the effect of reducing the acceptability of the model significantly $\left(\chi^{2}=42.46, p<.01\right)$. Each of the alternative models, which deleted the connection between memory capacity and phonological awareness, was found to have a significantly

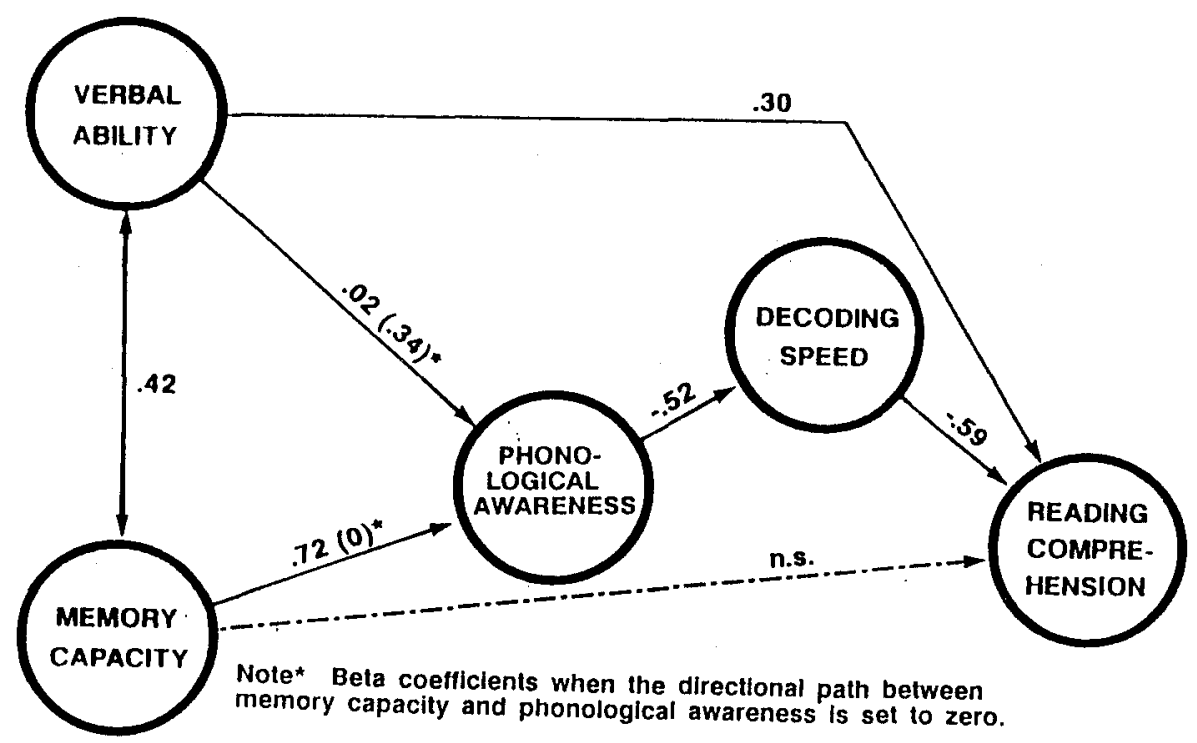

Fig. 2: $\quad$ LISREL model for second grade predictors of second grade decoding speed and reading comprehension 
lower fit than the actual proposed models when applying $\chi^{2}$ analyses for estimating significant differences in model fit.

These analyses would appear to demonstrate the primacy of memory in predicting phonological awareness and reading performance, and the direct effects of phonological awareness on decoding speed. However, in second grade, the influence of memory on reading comprehension would appear to be only indirect through its direct influence on phonological awareness and decoding speed. Decoding speed was not directly influenced by memory capacity in any model, but taking memory capacity out of the models resulted in an unacceptable model fit, indicating that memory capacity was a necessary factor in explaining the structure of relationships among the factors.

The results of these LISREL analyses are somewhat unsettling given the evidence that phonological recoding is likely a primary source of influence on working memory in reading (Brady et al., 1983; Liberman et al., 1977; Mann et al., 1980; Mark et al., 1977; Siegel/Linder 1984; Siegel/Ryan 1989). Our results appear to show the primacy of memory span in predicting performance on phonological awareness tasks. The following section assesses the relationship between phonological awareness and memory capacity beginning at an earlier age than the LISREL analyses just described.

\section{Phonological recoding and verbal memory}

Hitch/Woodin/Baker (1989) found differences in performance of preschoolers (6-7 years of age) and older children (10-11 years of age) on tasks used to measure phonological recoding in memory retrieval. Younger children recalled groups of objects with similar shapes less well than groups of objects with similar sounding labels, but of varying shape. In contrast, older children recalled the names of less objects in groups with similar sounding labels than compared with groups of similar shaped objects. Hitch et al. (1989) interpreted these results as indicating that older children were more likely than younger children to spontaneously phonologically recode information to be recalled. Younger children appeared to recode other information, such as the shape of the objects, in their recall processes. 
The results reported in this section provide further information concerning the development of phonological recoding in working memory. Word span was measured at three ages $(4,6$, and 8 years of age), and phonological awareness was measured twice (at 6 and 8 years of age). Phonological awareness usually does not develop until the age of five or older. The phonological awareness measures chosen for these analyses were the first and last sound oddity tasks from the Bradley/Bryant oddity tasks, given that these tasks are not dependent on alphabetic knowledge (Näslund 1992). Partial cross-lag correlations among these measures were performed. All partial cross-lag correlations are shown controlling for preschool letter knowledge. The pattern of results suggest developmental differences in the relationship between phonological awareness and verbal memory.

In Figure 3, there is surprisingly no significant correlation between verbal memory at age 4 and at age 6 . However, there is a significant correlation between verbal memory at age 4 and phonological awareness at age 6 . This implies that although verbal memory at age 4 is not a stable predictor of verbal memory at age 6 , verbal memory does predict later phonological awareness. In addition, verbal memory at age 4 does predict verbal memory and phonological awareness at age 8 (controlling for verbal memory and letter knowledge at age 6). Verbal memory would appear to be a relatively stable factor in the long run (over a four year period), but not between the ages of 6 and 8 . The partial cross-lag correlations among the verbal memory and phonological awareness measures between the ages of 6 and 8 demonstrate an interesting pattern. Although phonological awareness predicts memory span at age 6 more so than memory span at age 4 does, phonological awareness at age 6 does not predict verbal memory at age 8. Instead, verbal memory at age 6 predicts phonological awareness at age 8 . This direction of influence is also suggested by the partial cross-lag correlations at age 8 between verbal memory and phonological awareness. An additional analysis supports the hypothesis that phonological recoding in verbal memory is present in some children at the age of six independent of letter knowledge. The correlation between intra-individual differences in verbal memory and the combined phonological oddity task in kindergarten was significant controlling for preschool letter knowledge $(r=.57, p<0.0001)$. This reflects the findings in other studies concerned with phonological awareness and its relationship to verbal memory. Larger discrepancies in recall of phonologically similar and dissimilar lists of verbal information most likely reflects interference due to spontaneous phonological recoding of information. 


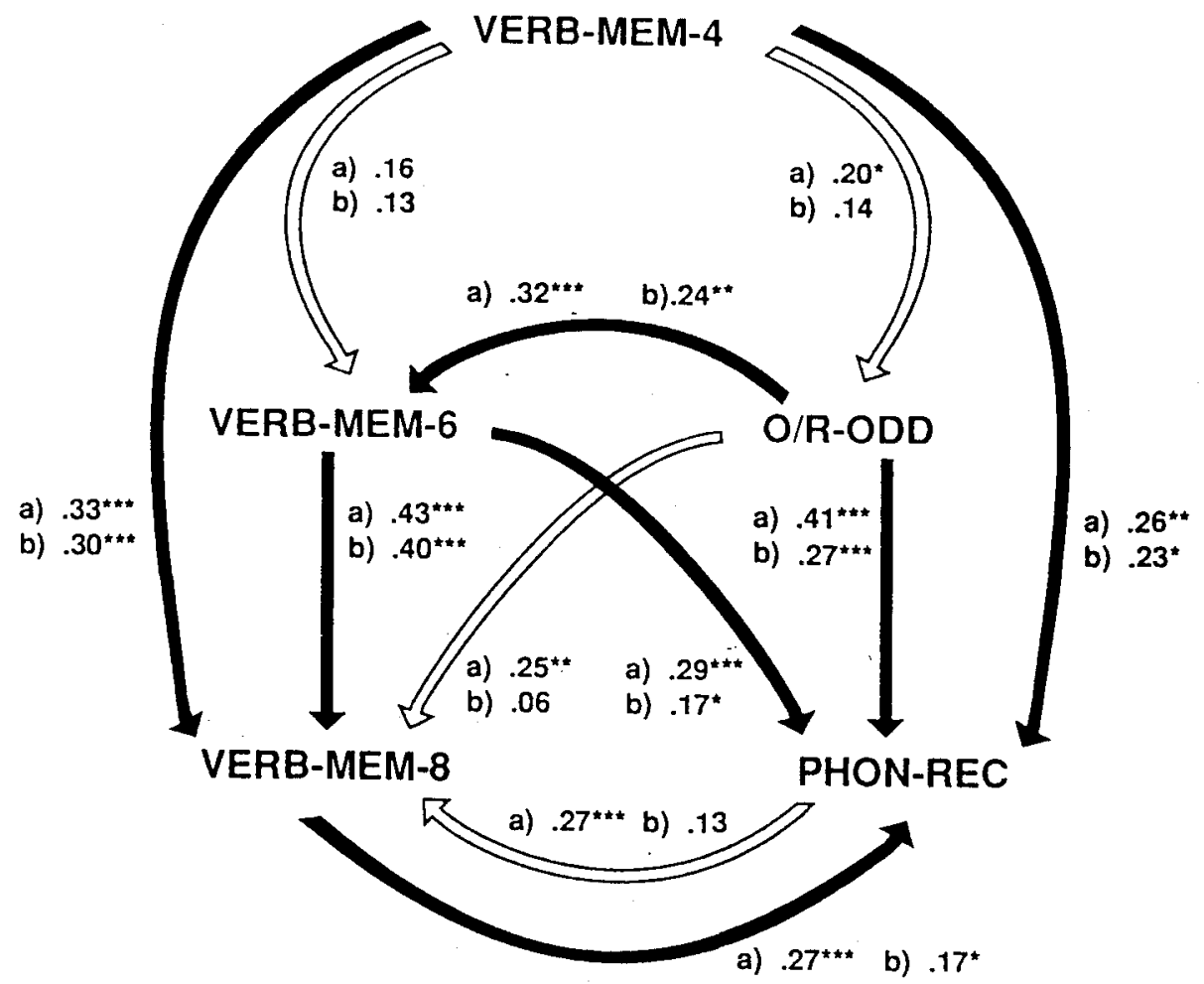

a) first order correlation

b) partial correlation controlling for previous measurement and letter knowledge

${ }^{\star} \mathrm{p}<.05 \quad{ }^{\star \star} \mathrm{p}<.01 \quad{ }^{\star \star \star} \mathrm{p}<.001$

Fig. 3: $\quad$ Partial cross-lag correlations among word span (VERB-MEM), onset \& rhyme oddity (O/R-ODD), and phonological recoding (PHON-REC) variables

To summarize these results and their implications, it would appear that verbal memory at all ages predicts children's performance on phonological awareness tasks at both testing times. However, the lack of significant correlation between verbal memory at age 4 and age 6 together with the significant correlation of phonological awareness at age 6 with verbal memory at age six would suggest that at about age six, phonological awareness may elicit phonological recoding of verbal information in some children. Development of phonological awareness around the age of six may actually ex- 
plain the lack of significant correlation of verbal memory from ages four to six, given that children differentially develop phonological awareness at around age five to seven.

Children also varied in their letter knowledge at the time of testing at age 6 . This prompted including letter knowledge in the analyses. The next section addresses the issue of the influence of early alphabetic knowledge on the development of phonological awareness. Specifically, does phonological awareness predict reading performance independently of early alphabet knowledge?

Is letter knowledge necessary for the development of phonological awareness?

Lundberg (1987) has responded directly to this question. Children in Scandinavia begin formal instruction in reading at the age of about seven, two years later than in the U.S., and one year later than in Germany. Letter knowledge is therefore very minimal for Scandinavian and German children in the kindergarten years. In our own sample, the average number of letter or letter sounds correctly identified by children was 5.8. The median number was even lower than this (3 letter or letter sounds correctly identified). Results with our German sample concerning preliterate phonological awareness development reflect the same findings as Lundberg's studies (1987; see also Lundberg/Høien 1991; Lundberg/Olofsson/Wall 1980). However, the large variation in tasks used to assess metalinguistic and phonological awareness elicit varying results.

The means and medians of all metalinguistic tasks and their correlations with the early grade school tasks are found in Table 1. Tasks pertaining to analysis or synthesis of onset/rime units, and the segmenting of syllables were found to be the most difficult for our sample of children in the last month of kindergarten. Vowel and rhyme detection tasks, syllable blending and counting, and repeating nonsense words displayed a ceiling effect.

Not all of the phonological awareness tasks administered in this study predicted later reading skills (see correlations on Table 2). Syllable counting and segmenting in prereaders have been highly predictive of reading in other, mainly English-speaking, studies. Almost all of the German children 
Tab. 1: $\quad$ Means and medians for metalinguistic tasks given in kindergarten

\begin{tabular}{lll}
\hline Preschool Tasks & Mean & Median \\
\hline Onset-Oddity & $34 \%$ & $44 \%$ \\
Onset/Rime-Blend & $54 \%$ & $50 \%$ \\
Syllable Segmenting & $64 \%$ & $65 \%$ \\
Rhyme-Oddity & $68 \%$ & $78 \%$ \\
Pseudoword Repetition & $69 \%$ & $70 \%$ \\
Mid-Vowel-Oddity & $70 \%$ & $78 \%$ \\
Syllable Blending & $75 \%$ & $80 \%$ \\
Syllable Counting & $84 \%$ & $80 \%$ \\
Sound-in-Word & $88 \%$ & $100 \%$ \\
Rhyme Detection & $92 \%$ & $100 \%$ \\
\hline
\end{tabular}

Tab. 2: $\quad$ Correlations of preschool psycholinguistic tasks and letter knowledge with grammar school measures

\begin{tabular}{llllll}
\hline & \multicolumn{5}{c}{ EARLY GRADE SCHOOL TASKS } \\
Preschool Tasks & COMP & $\begin{array}{l}\text { WORD- } \\
\text { WEC }\end{array}$ & PWORD- & W-DISC & PHON- \\
& & DEC & & REC \\
\hline $\begin{array}{l}\text { Onset \& Rhyme-Oddity } \\
\text { (Combined Tasks) }\end{array}$ & .54 & -.43 & -.38 & .41 & .50 \\
Onset-oddity & .43 & -.38 & -.33 & .33 & .35 \\
Onset/Rime-Blend & .25 & -.26 & -.19 & $.16^{*}$ & .22 \\
Syllable Segmenting & $-.02^{*}$ & $.01^{*}$ & $.06^{*}$ & $.01^{*}$ & $.01^{*}$ \\
Rhyme-Oddity & .48 & -.32 & -.28 & .36 & .49 \\
Pseudoword-Repeat & .19 & -.27 & -.28 & .17 & .26 \\
Middle Vowel-Oddity & .22 & $-.09^{*}$ & $-.13^{*}$ & .20 & .34 \\
Syllable Blending & $.14^{*}$ & -.28 & -.24 & $.16^{*}$ & $.07^{*}$ \\
Syllable Counting & $.09^{*}$ & $-.11^{*}$ & $-.16^{*}$ & $.03^{*}$ & $.10^{*}$ \\
Sound in Word & .31 & $-.16^{*}$ & $-.12^{*}$ & .17 & .35 \\
Rhyme Detection & .35 & $-.13^{*}$ & -.17 & .17 & .26 \\
Letter Knowledge & .36 & -.37 & -.32 & .30 & .35 \\
\hline
\end{tabular}

COMP=Reading Comprehension, WORD-DEC $=$ Word Decoding Speed

PWORD-DEC $=$ Pseudoword Decoding Speed, W-DISC $=$ Word Discrimination PHON-REC=Phonological Recoding (Awareness)

* $\mathrm{p}>0.05$, nonsignificant 
in this study were prereaders in the last month of kindergarten. Given that most English speaking kindergartens teach formal reading skills, prereaders in English and American studies are younger, and likely less cognitively mature than the German children in this study. The advanced age, and low level of alphabetic knowledge in our sample provided an opportunity to test whether Lundberg's or Morais' and Ehri's hypotheses were correct: Is letter knowledge necessary or not for developing phonological awareness? In addition, and more importantly, does preschool phonological awareness predict later reading performance independent of alphabetic knowledge? In order to answer this question, regression analyses were performed for each metalinguistic task that correlated significantly with either reading comprehension, word decoding or pseudoword decoding speed. The scores of onset and rhyme oddity are combined for these regressions as a phonological awareness variable. The first set of regression analyses (see Table 3 ) have verbal ability, verbal memory, and letter knowledge as the first three regressors, and enter the various metalinguistic measures as the fourth step. As shown, only the onset/rhyme oddity, onset/rime blending, and rhyme recognition tasks were significant in at least one reading measure after controlling for letter knowledge.

These results reflect Bryant/Bradley/Maclean/Crossland's (1989) findings that sensitivity to rhyme is a likely first step toward metalinguistic awareness. Bryant et al. (1989) found that early knowledge of nursery rhymes (at ages 3 and 4) predicted later linguistic analysis skills. These analysis skills allow a preliterate child to detect sounds and sound changes within syllabic word components, which is reflected in the oddity and blend tasks.

This first set of regression analyses revealed that only a subset of the metalinguistic awareness skills assessed in kindergarten predict later reading performance independently from alphabet knowledge. In order to test whether some forms of metalinguistic awareness may actually be necessary to learn the alphabetic principle (see Tunmer/Rohl 1991), a second set of regression analyses were performed. For these analyses, letter knowledge was placed last in the models. Only the metalinguistic tasks which demonstrated significance in the amount of variance explained in at least one of the reading measure.

Results in Table 4 show that letter knowledge still explains a significant proportion of the variance in the reading measures after accounting for the variance in onset/rime blending and rhyme detection, but not after accounting for the variance explained by onset/rhyme oddity. These results suggest 
Tab. 3: $\quad$ Hierarchical regression models for comparing the effects of $O / R-O D D$ (Onset \& Rhyme Oddity), OIR-BLEND (Onset/Rime-Blend), and PWORDREP (Pseudoword-Repeat) tasks with LETT-KNOW (Letter Knowledge), VERB-MEM (Word Span), and VERB-IQ (Verbal Ability) on early elementary school reading and phonological awareness measures

\begin{tabular}{llllll}
\hline \multicolumn{5}{c}{ EARLY ELEMENTARY SCHOOL MEASURES } \\
ORDER OF & COMP & WORD- & PWORD- & W-DISC & PHON- \\
ENTRY & & DEC & DEC & & REC \\
\hline 1. VERB-IQ & $.16^{* * *}$ & $.03^{*}$ & $.05^{* *}$ & $.08^{* * *}$ & $.09 * * *$ \\
2. VERB-MEM & .01 & $.06^{* * *}$ & $.09^{* * *}$ & $.03^{*}$ & $.04^{* *}$ \\
3. LETT-KNOW & $.04^{* *}$ & $.11^{* * *}$ & $.04^{*}$ & $.05^{* *}$ & $.08^{* * *}$ \\
- & & & & & \\
4. O/R-ODD & $.09^{* * *}$ & $.08^{* * *}$ & $.04^{*}$ & $.05^{* *}$ & $.09 * * *$ \\
4. O/R-BLEND & $.03^{*}$ & .02 & .00 & .01 & .01 \\
4. PWORD-REP & .00 & .01 & .01 & .00 & .00 \\
\hline
\end{tabular}

$* \mathrm{p}<0.05{ }^{* *} \mathrm{p}<0.01 * * * \mathrm{p}<0.001$

Tab. 4: $\quad$ Hierarchical regression models for comparing the effects of LETT-KNOW with $O / R-O D D$ and $O / R-B L E N D$ on early elementary school reading and phonological awareness measures

\begin{tabular}{llllll}
\hline & \multicolumn{5}{c}{ EARLY ELEMENTARY SCHOOL MEASURES } \\
$\begin{array}{l}\text { ORDER OF } \\
\text { ENTRY }\end{array}$ & COMP & $\begin{array}{l}\text { WORD } \\
\text { DEC }\end{array}$ & $\begin{array}{l}\text { PWORD- } \\
\text { DEC }\end{array}$ & W-DISC & PHON- \\
\hline REC
\end{tabular}

$$
{ }^{*} \mathrm{p}<0.05{ }^{* *} \mathrm{p}<0.01 * * * \mathrm{p}<0.001
$$


that onset/rhyme oddity measures may be tapping a primary cognitive factor in emergent literacy, which is independent of formal instruction in reading. Rhyme detection is likely a precursor to phonological awareness, as results from Bryant et al. (1989) would suggest. Facility with rhyme detection does not necessarily indicate presence of phonological segmentation ability. The onset/rime blending task does require phonological segmentation, and performance on this task is likely to be enhanced by the ability to represent sounds orthographically. It is therefore not surprising that a significant proportion of reading comprehension and word decoding would be explained by both letter knowledge and onset/rime blending. According to Tunmer/ Rohl (1991), this type of task may be more a measure of instruction in phonics than of actual phonological awareness.

In contrast, letter knowledge did not explain a significant proportion of the variance in any of the reading tasks when placed in the regression model after onset/rhyme oddity. According to the results found in this study, this task requires phonological analysis and segmentation, but not Letter Knowledge. The results found here support Bradley/Bryant's (1985), Lundberg's (1987), and Tunmer/Rohl's (1991) claim that phonological awareness can precede formal reading instruction, and even predict to a large extent future success in reading performance.

\section{General discussion}

This study supports evidence found in other longitudinal studies that metalinguistic (especially phonological) awareness, verbal memory, and general verbal ability (but to a lesser extent) as measured in kindergarten and early elementary school contribute to explaining later reading performance. Our results suggest that this finding is a fairly universal one, not only applying to the (irregular) English and (regular) Scandinavian language systems but also to the German langage system which is in between, as far as regularity is concerned. The structural equation models used in testing the most likely pattern of causal relations among these variables supported the hypothesis that memory span and phonological awareness as measured in kindergarten and in second grade are pivotal factors in predicting reading performance in second grade. Verbal ability was found to be of less importance in comparison with the other factors. In addition, results indicated that early alphabetic knowledge is not necessary for the development of phonological awareness. This does not support claims made by Ehri (1989), Morais et al. 
(1979), and Read et al. (1986) that phonological awareness does not arise spontaneously in the absence of familiarity with an alphabetic system and some instruction in phonetics. This result does support the position taken by Lundberg (1987), Lundberg/Høien (1991), and Tunmer/Rohl (1991) that phonological awareness can and does arise spontaneously before formal reading instruction, and that perhaps phonological awareness is a necessary precursor to acquiring the alphabetic principle.

In addition, it would appear that phonological awareness and verbal memory interact developmentally. Testing children in verbal memory span at ages four, six, and eight and phonological awareness at ages six and eight, indicates that emergent phonological awareness likely begins to influence verbal memory span of some children at some time between the ages of four and six. However, caution must be exercised in drawing conclusions based on these analyses. This investigation did not systematically rule out all possible intervening factors, besides preschool letter knowledge and literacy, to explain the longitudinal relationships found between verbal memory span and phonological awareness. Supporting evidence that some children in our sample were developing phonological recoding in working memory was found in comparing differential performance on word span tasks that used phonologically similar and dissimilar words.

Some researchers have argued that larger discrepancies between recall of phonologically similar and dissimilar lists of words is evidence for phonological recoding in working memory (Brady et al. 1983; Liberman et al. 1977; Mann et al. 1980; Mark et al. 1977; Shankweiler/Liberman/Mark et al. 1979). It is still difficult to definitively substantiate this claim, given that children with larger discrepancies are also usually those who perform better overall on memory tasks and are usually better readers. Evidence thus far in the literature certainly is convincing that a causal relationship between phonological awareness and memory development is highly likely. Although verbal memory and reading are strongly correlated, more proof is needed to substantiate claims that the developmental of phonological awareness is responsible for changes in a child's heuristic for storing verbal information, which in turn increases reading performance.

Another caution is Ehri's (1989) criticism of the claim that phonological awareness is a causal facilitating factor in reading acquisition that necessarily precedes literacy instruction. Not all children who demonstrate early phonological awareness deficits become dyslexic or poor readers. Stanovich (1989) has countered this argument by citing evidence that very few chil- 
dren who are phonologically aware in preschool or kindergarten develop reading problems. Phonological awareness may arise spontaneously for some children in the absence of reading instruction (Lundberg 1987). On the other hand, it may not be exclusively developmental. Other children may develop these skills after they enter formal instruction and begin learning reading skills. Direct learning about letter-sound relationships may trigger phonological awareness for those who were not phonemically aware in preschool. Others may not fully develop phonological awareness, and may need to rely on some other heuristic for holding verbal information in working memory while reading. For this last group of children, reading is going to be a difficult task. Their reading skills will be far below those children who phonologically recode information while reading. For dyslexics, this does not represent a cognitive deficit in the traditional sense. Intelligence, verbal comprehension, and even working memory may all be average or above average. It's the presence of spontaneous phonological recoding of verbal information in average and good readers that actually seems to define dyslexia in some groups of poor readers. Dyslexia would then be defined as lack of a certain ability to segment speech sounds that arises spontaneously in many children. This condition may actually be somewhat historical in nature. As literacy in humans emerges, changes in cognition are likely, especially in the literacy "revolutions" throughout history. The spread of literacy in the Sudan during the spread of Islam in the tenth century is a case in point for the sudden emergence of a new skill revolutionizing human thought and cognition.

More research needs to be done on linguistic environments that hinder or facilitate spontaneous phonological awareness in individuals. We may be coming closer to understanding the cognitive mechanisms and environments that are responsible for phonological awareness, especially in the most recent research on infants' phonemic discrimination during the first year of life. Babies begin life with the ability to distinguish between phonemes that adults no longer discriminate. As time passes, they build classes of phonemes in their own languages. Losing this sound discrimination and building classes of phonemes helps us understand speech spoken by the many individuals in our language group. At six months, they can still distinguish phonemes of non-native languages, but perform almost as adults in not being able to distinguish phonemes within certain linguistic classes. At ten to twelve months, babies perform like adults in their inability to distinguish phonemes within the same class in native and non-native languages. This also corresponds to the time when first words are learned. It is after this time that whole words become children's linguistic realities, and chil- 
dren do not segment or distinguish among phonemes until just about the time they begin to learn to read (Smith 1986). Perhaps Maclean/Bryant/ Bradley's (1987) findings indicate that learning and reciting nursery rhymes at an early age is helping to trigger this lost discrimination skill. Children cannot segment speech consciously yet at the age of three or four years, but some phonological awareness may be triggered by such exposure and recitation practice.

Results of this study appear to support findings of other studies that show the importance of metalinguistic skills in emergent reading. There were also differences found in comparison with some of the other studies mentioned earlier (Ehri 1989; Morais et al. 1979; Read et al., 1986). The German findings were similar to the Swedish results (Lundberg et al. 1988) in terms of letter knowledge not being necessary for the development of phonological awareness. Differences likely reflected the fact that German and Swedish children are older when they learn to read in comparison to other industrial nations. Their psycholinguistic development at about age six is therefore not shaped by early literacy skills. Despite a lack of rudimentary literacy ability, psycholinguistic development does not appear to be hindered, as evidenced by ceiling level performance in easier metalinguistic tasks. In addition, phonological awareness also develops despite lack of letter knowledge in German (as well as Swedish) children. This suggests that phonological awareness is a more naturally occurring developmental stage which can (as possibly should) precede learning to read.

\section{References}

Bradley, L. \& Bryant, P. (1985). Rhyme and reason in reading and spelling. Ann Arbor, MI: University of Michigan Press.

Brady, S., Shankweiler, D., \& Mann, V. (1983). Speech perception and memory coding in relation to reading ability. Journal of Experimental Child Psychology, 35, 345367.

Burgemeister, B., Blum, L., \& Lorge, J. (1972). Columbia Mental Maturity Scale. New York: Harcourt Brace.

Brügelmann, H. (1986). Lese- und Schreibaufgaben für Schulanfänger. Universität Bremen: Studiengang Primarstufe. 
Bryant, P., Bradley, L., Maclean, M., \& Crossland, J. (1989). Nursery rhymes, phonological skills and reading. Journal of Child Language, 16, 407-428.

Case, R., Kurland, D.M., \& Goldberg, J. (1982). Operational efficiency and the growth of short-term memory span. Journal of Experimental Child Psychology, 33, 386-404.

Daneman, M. \& Blennerhassett, A. (1984). How to assess the listening comprehension skills of prereaders. Journal of Educational Psychology, 76, 1372-1381.

Eggert, D. (Ed.) (1978). Hannover-Wechsler-Intelligenztest für Vorschulkinder (HAWIVA). Bern: Huber.

Ehri, L. (1989). The development of spelling knowledge and its role in reading acquisition and reading disability. Journal of Learning Disabilities, 22(6), 356-365.

Foorman, B.R., Francis, D.J., Novy, D.M., \& Liberman, D. (1991). How letter-sound instruction mediates progress in first grade reading and spelling. Journal of Educational Psychology, 83(4), 456-469.

Goodman, K.S. (1967). Reading: A psycholinguistic guessing game. Journal of the Reading Specialist, 4, 126-135.

Hitch, G.J., Woodin, M.E., \& Baker, S. (1989). Visual and phonological components of working memory in children. Memory and Cognition, 17(2), 175-185.

Jansen, H., Knorn, P., Mannhaupt, G., Marx, H., Beck, M., \& Skowronek, H. (1986). Bielefelder Screening zur Vorhersage von Lese-Rechtschreibschwierigkeiten. Universität Bielefeld, SFB 227, F.R.G.

Jöreskog, K.G., \& Sörbom, D. (1984). LISREL VI: Analysis of structural relationships by the method of maximum likelihood. Mooresville, IN: Scientific Software, Inc.

Juel, C. (1988). Learning to read and write: A longitudinal study of 54 children from first through fourth grades. Journal of Educational Psychology, 80, 437-447.

Liberman, I.Y., Shankweiler, D., Liberman, A.M., Fowler, C., \& Fischer, F.W. (1977). Phonetic segmentation and coding in the beginning reader. In A.S. Reber \& D.L. Scarborough (Eds.), Toward a psychology of reading: The proceedings of the CUNY conferences. 297-225. Hillsdale, NJ: Erlbaum.

Lundberg, I. (1987). Are letters necessary for the development of phonological awareness? Cahiers de Psychologie, 7, 472-475.

Lundberg, I., Frost, J., \& Petersen, O.-P. (1988). Effects of an extensive program for stimulating phonological awareness in preschool children. Reading Research Quarterly, 23, 263-284. 
Lundberg, I., Olofsson, Å., \& Wall, S. (1980). Reading and spelling skills in the first school years predicted from phonemic awareness skills in kindergarten. Scandinavian Journal of Psychology, 21, 159-173.

Lundberg, I. \& Høien, T. (1991). Initial enabling knowledge and skills in reading acquisition: Print awareness and phonological segmentation. In D.J. Sawyer \& B.J. Fox (Eds.), Phonological awareness in reading: The evolution of current perspectives. 73-96. New York: Springer-Verlag.

Maclean, M., Bryant, P., \& Bradley, L. (1987). Rhymes, nursery rhymes and reading in early childhood. Merrill-Palmer Quarterly, 33, 255-282.

Mann, V.A., Liberman, I.Y. \& Shankweiler, D. (1980). Children's memory for sentences and word strings in relation to reading ability. Memory \& Cognition, 8(4), 329-335.

Mark, L.S., Shankweiler, D., Liberman, I.Y., \& Fowler, C.A. (1977). Phonetic recoding and reading difficulty in beginning readers. Memory \& Cognition, 5(6), 623-629.

Morais, J., Cary, L., Alegria, J., \& Bertelson, P. (1979). Does awareness of speech as a sequence of phones arise spontaneously? Cognition, 7, 323-331.

Näslund, J.C. (1992). How do preschool letter knowledge and metalinguistic skills affect later reading and spelling performance? Manuscript submitted for publication.

Näslund, J.C. \& Schneider, W. (1991). Longitudinal effects of verbal ability, memory capacity, and phonological awareness on reading performance. European Journal of Psychology of Education, 6(4), 375-392.

Perfetti, C., Beck, I., Bell, L., \& Hughes, C. (1987). Phonemic knowledge and learning to read are reciprocal: A longitudinal study of first grade children. Merrill-Palmer Quarterly, 33, 283-319.

Read, C., Zhang, Y., Nie, H., \& Ding, B. (1986). The ability to manipulate speech sounds depends on knowing alphabetic reading. Cognition, 24, 31-44.

Schneider, W. \& Näslund, J. (1992). Cognitive prerequisites of reading and spelling: A longitudinal approach. In A. Demetriou, M. Shayer, \& A. Efklides (Eds.), NeoPiagetian theories of cognitive development: Implications and applications for education. 256-274. London: Routledge.

Shankweiler, D., Liberman, I.Y., Mark, L.M., Fowler, L.A., \& Fischer, F.W. (1979). The speed code and learning to read. Journal of Experimental Psychology: Human learning and memory, 5, 531-545.

Siegel, L.S. \& Linder, B.A. (1984). Short-term memory process in children with reading and arithmetic abilities. Developmental Psychology, 20, 200-207. 
Siegel, L.S. \& Ryan, E.B. (1989). The development of working memory in normally achieving and subtypes of learning disabled children. Child Development, 60, 973980.

Skowronek, H. \& Marx, H. (1989). The Bielefeld longitudinal study on early identification of risks in learning to read and write: Theoretical background and first results. In M. Brambring, F. Lösel, \& H. Skowronek (Eds.), Children at risk: Assessment, longitudinal research, and intervention. 245-267. New York: De Gruyter.

Smith, P.T. (1986). The development of reading: The acquisition of a cognitive skill. In P. Fletcher \& M. Garman (Eds.), Language acquisition: Studies in first language acquisition. 475-493. Cambridge, GB: Cambridge University Press.

Stanovich, K.E. (1989). Various varying views on variation. Journal of Learning Disabilities, 22(6), 366-369.

Stanovich, K.E., Cunningham, A.E, \& Feeman, D.J. (1984). Intelligence, cognitive skills, and early reading progress. Reading Research Quarterly, 19, 278-303.

Tewes, U. (1985). Hamburg-Wechsler-Intelligenztest für Kinder (HAWIK). Bern: Huber.

Tunmer W.E. \& Rohl, M. (1991). Phonological awareness and reading acquisition. In D.J. Sawyer \& B.J. Fox (Eds.), Phonological awareness in reading: The evolution of current perspectives. 1-30. New York: Springer-Verlag.

Vellutino, F.R. (1991). Introduction to three studies on reading acquisition: Convergent findings on theoretical foundations of code-oriented versus whole-language approaches to reading instruction. Journal of Educational Psychology, 83(4), 437443.

Weinert, F.E. \& Schneider, W. (Eds.) (1987). The Munich Longitudinal Study on the Genesis of Individual Competencies (LOGIC). Report No. 2: Documentation of assessment procedures used in waves one to three. Munich, FRG: Max Planck Institute for Psychological Research.

Weinert, F.E. \& Schneider, W. (Eds.) (1991). The Munich Longitudinal Study on the Genesis of Individual Competencies (LOGIC). Report No. 7: Results of wave 4. Munich, FRG: Max Planck Institute for Psychological Research.

Weinert, F.E. \& Schneider, W. (Eds.) (1992). The Munich Longitudinal Study on the Genesis of Individual Competencies (LOGIC). Report No. 8: Results of wave 5. Munich, FRG: Max Planck Institute for Psychological Research. 